\title{
COMMISSION 27: VARIABLE STARS (ÉTOILES VARIABLES)
}

\author{
Report of Meetings
}

President ad Interim: M. W. Feast.

\section{Administrative Session, 21 August 1973}

The President announced with regret the death of Dr A. C. Banerji, a member of the Commission. He also recalled the recent deaths of two of the most distinguished workers in the field of variable stars during the present century, Dr A. H. Joy and Dr H. Shapley (both at one time members of the Commission). The composition of the new Organizing Committee for submission to the IAU Executive was approved. A list of new members of the Commission was approved. Plans for a symposium in Moscow in 1974 on 'Variables as a Key to the Evolution of Stars and Stellar Systems' and a colloquium in Budapest in 1975 on 'Multiple Periodic Variable Stars' were announced. The President asked for views on the future of the Report on Variable Stars published in Transactions. In view of the large amount of work this Report entailed, he felt it only worth continuing if it was fairly extensively used and he had some doubts as to whether this was the case. None of the members present appeared to have strong views for or against continuing the Report and it was agreed that the incoming Organizing Committee should decide, after consultation with Commission members and the IAU Executive, whether to continue the Reports in the present or another form or whether to drop them entirely. The request from the Executive that each Commission compile a list of priorities and expected developments in its field was discussed. The meeting concurred with the view of the President (Trans. IAU XVA, p. 313) that such a list could easily be misused and asked him to urge the Executive not to repeat this request in future years. There was some discussion of a circular letter from the Moscow Variable Star Bureau asking for suggestions for changes in the General Catalogue of Variable Stars. It was announced that Mrs H. Sawyer Hogg's third catalogue of variable stars in globular clusters was now in the hands of the printer and that she was already preparing for the fourth edition which she envisaged publishing within the next five years. A motion that the annual subvention from the IAU to the Moscow Variable Star Bureau for their work on the General Catalogue of Variable Stars and related programmes be continued for the next three years, was proposed by Dr D. H. McNamara, seconded and carried unanimously. The difficulty experienced by observers in correctly identifying faint variable stars was raised. It was agreed that everything should be done to provide good maps (many existing maps are inadequate and for many variables there are no maps at all). In some cases variables will only be positively identified by rediscovering them. A small informal group (Rodgers, Kunkel, Feast) was set up to look into this problem. They later co-opted Miss Hoffleit into the group and it was agreed to work in close collaboration with the Moscow Bureau. The Commission voted for the continuation of four Working Groups under the following chairmen: Mrs H. Sawyer Hogg (Variables in Globular Clusters), Prof. P. F. Chugainov (Flare Stars), Dr F. Zwicky (Supernovae), Dr S. C. B. Gascoigne (Variables in the Magellanic Clouds). The possible need for Commission rules (suggested by the IAU Executive) was referred to the incoming Organizing Committee. However it was felt that the Commission functioned well without formal rules other than the by-laws of the IAU.

\section{Scientific Meeting, 25 August 1973}

The meeting began with a talk by Dr A. D. Code on observations of variable stars from outside the atmosphere. After a break the meeting continued as an informal discussion group organized by 
Dr Lesh and Dr Aizenman on $\beta$ CMa stars. A letter from Dr Van Hoof asking for collaboration in a programme on $v^{2}$ Pup was discussed at this meeting.

\section{Other Meetings}

Commission 27 was responsible for a large part of the organization of the Joint Meeting (Commissions $27,35,40,42,44,48)$ on Variable XR Sources which occupied a whole day (23 August 1973). Speakers were:

Tananbaum, Parkinson, Boyd, Petersen: XR Observations.

Hutchings, Garrison, Kemp, Vidal, Wilson: Optical Observations.

Wade, Miley: Radio Observations.

Kundu, Rees: Theory

Commission 27 was responsible for much of the organization of a Joint Meeting (Commissions $25,27,34,37,40$ ) on Very Compact $H_{I I}$ regions (which included some work on Variable OH/IR sources), (27 August 1973, half day). Speakers were:

Habing, Mezger, R. D. Davies, Palmer, Zuckerman, Baars, Hoglund, Donn, Kahn.

Commission 27 was represented on the organizing of the following Joint Discussions:

22 August 1973: The Outer Layers of Novae and Supernovae.

24 August 1973: Stellar Infrared Spectroscopy.

27 August 1973: Kinematics and Ages of Stars in the Solar Neighbourhood.

28 August 1973: Very Short Time Scale Phenomena. 